ARTÍCULO

\title{
Profesores en dictadura y democracia: perspectiva biográfica de docentes en fin de carrera profesional*
}

\author{
Rosa Orellana-Fernández \\ Eugenio Merellano-Navarro' \\ Adolfo Berríos-Villarroel' \\ Alejandro Almonacid-Fierro"
} (D)

\section{RESUMEN}

Este artículo analiza las trayectorias profesionales de cinco profesoras en dos momentos importantes en la historia de Chile: la dictadura y el regreso a la democracia. Nos apoyamos en el método biográfico con el fin de comprender, desde las voces de las protagonistas sus experiencias significativas. Estas se analizaron según los preceptos de la teoría fundamentada. Los resultados describen una trayectoria profesional marcada por el miedo y la desconfianza. Desprendemos que los últimos años de trabajo ponen de manifiesto el desaliento frente a los cambios educativos que reducen la autonomía y la colaboración. Las profesoras analizan la permanente búsqueda de resultados estandarizados y experimentan una profunda decepción frente a al régimen democrático que instalado al término de la dictadura de Pinochet. Suponemos que estos aspectos organizan la identidad del docente en final de carrera y que nutren una forma de sufrimiento ordinario.

\section{PALABRAS CLAVES}

profesores; biografía; experiencias profesionales; identidad docente.

\footnotetext{
*Este artículo presenta parte de los resultados del proyecto DIUA112-2017/FONDECYT n. 319041 que tiene por objetivo analizar la trayectoria de docentes en fin de carrera y cómo sus experiencias de trabajo, en contextos de profunda transformación del sistema educativo y de la labor docente, configuran la identidad docente, apoyado por la Universidad Autónoma de Chile y Fondo Nacional de Desarrollo Científico y Tecnológico de la Comisión Nacional de Investigación Científica y Tecnológica (CONICYT). 'Universidad Autónoma de Chile, Talca, Chile. "Universidad Católica del Maule, Talca, Chile.
} 
TEACHERS IN DICTATORSHIP AND DEMOCRACY:

\title{
BIOGRAPHICAL PERSPECTIVE OF TEACHERS AT THE END OF A PROFESSIONAL CAREER
}

\begin{abstract}
This paper analyzes the professional trajectories of five teachers at two important moments in the history of Chile: dictatorship and the return to democracy. We rely on the biographical method in order to understand, from the voices of the leading figures, their significant experiences. These were analyzed according to the Grounded Theory precepts. The results describe a career path marked by fear and distrust. We conclude that the last years of work reveal discouragement with the educational changes that structure the loss of autonomy and collaboration. The teachers analyze the permanent search for standardized results and experience a deep disappointment with the democratic regime installed at the end of the Pinochet dictatorship. We assume that these aspects organize the identity of the teacher at the end of the career and also encourage a form of suffering.
\end{abstract}

KEYWORDS

teachers; biography; professional experiences; teaching identity.

\section{PROFESSORES DE DITADURA E DEMOCRACIA: PERSPECTIVA BIOGRÁFICA DE PROFESSORES NO FINAL DE UMA CARREIRA PROFISSIONAL}

RESUMO

O objetivo deste artigo é analisar as trajetórias professionais de cinco professores em dois momentos importantes da história do Chile: a ditadura e o retorno à democracia. Contamos com o método biográfico para entender, pelas vozes dos protagonistas, suas experiências. Estes foram analisados de acordo com os preceitos da teoria fundamentada. Os resultados descrevem uma trajetória de carreira marcada pelo medo e desconfiança. Concluímos que os últimos anos de trabalho revelam desânimo com as mudanças educacionais que estruturam a perda de autonomia e colaboração. Os professores analisam com tristeza a busca permanente de resultados padronizados e experimentam um profundo desapontamento com o regime democrático instalado no final da ditadura de Pinochet. Assumimos que esses aspectos organizam a identidade do professor no final da carreira e esses aspectos também estimulam uma forma de sofrimento.

PALAVRAS-CHAVE

professores; biografia; experiências profissionais; identidade docente. 


\section{INTRODUCCIÓN}

Las reformas operadas durante la dictadura militar (1973-1990) y continuadas con el retorno a la democracia durante la década de los 90 terminaron de manera definitiva con el Estado docente. ${ }^{1}$ Los principios económicos neoliberales que guiaron las políticas públicas educacionales de los años 80 generaron transformaciones que redefinieron los derechos y deberes que aseguraba el Estado para el sistema educacional (Bellei, 2013; Elacqua, 2012; Valenzuela, Bellei y de Los Rios, 2010; Villalobos y Quaresma, 2015), generando cambios en las condiciones laborales de los docentes (Núñez, 2015) y en los programas de formación de profesores (Ávalos et al., 2010).

Según Moreno-Doña y Gamboa (2014), los cambios que se aplicaron progresivamente después del golpe militar de 1973 se dividen en dos periodos. El primero, 1973-1979, se caracteriza por una fuerte represión y control de las libertades civiles que tienen como objetivo desarticular los sindicatos docentes, agrupaciones estudiantiles y toda organización de carácter educativo. En este sentido, para tener mayor control sobre el cuerpo docente, el decreto de ley n. 678 crea en 1974 el Colegio de Profesores bajo la tutela de un grupo radical de derecha. El segundo periodo, 1980-1990, se focalizó en la introducción de mecanismos de mercado para gestionar y financiar la educación pública del país.

A nivel constitucional, la ley n. 18.962, Ley Orgánica Constitucional de Enseñanza (LOCE), operacionalizó el nuevo rol que asumió el Estado en la gestión y financiamiento de la educación pública del país. En este escenario, la adopción de una lógica de mercado, que favorece una mayor participación del sector privado en la educación, provocó el fin del Estado docente para dar paso a un Estado subsidiario. Para Cox (2012), esta nueva configuración estatal tuvo un doble efecto. Por una parte, restringió los deberes y las atribuciones del Estado a través de un vasto plan de descentralización desde el Ministerio de Educación hacia las autoridades comunales (municipalización). Por otra parte, introdujo mecanismos financieros basados en la competencia entre establecimientos por matrícula de alumnos. Inspirado en el sistema de voucher, el nuevo modelo canalizó los recursos a través de un subsidio otorgado a cada sostenedor (administrador o propietario del establecimiento educacional) según el promedio mensual de asistencia de los alumnos. Así, bajo la óptica de que la competencia es un mecanismo eficiente para mejorar la calidad, en 1988 se crea el Sistema de Información y Medición de la Calidad de la Educación (SIMCE). Esta tiene hasta el día de hoy, el propósito de entregar información en cuanto a los resultados escolares en pruebas estandarizadas nacionales para que los padres y apoderados puedan elegir un establecimiento educacional en base a sus resultados.

En consecuencia, el proceso de descentralización y privatización que experimenta la educación chilena durante las décadas ochenta y noventa tiene como consecuencia un aumento progresivo de la brecha entre los establecimientos públicos y privados. Operando bajo las reglas de competencia y eficacia que ofrece

1 Según Reyes (2014), la historiografía califica como Estado docente al periodo que caracteriza a los sistemas educativos latinoamericanos desde los inicios del siglo XIX y gran parte del siglo XX, donde el Estado está cargo de la construcción y gestión de la escuela pública. 
el nuevo modelo de cuasi-mercado (Corvalán y Román, 2012; Santos y Elacqua, 2016; Picazo, 2013) y con un sistema democrático condicionado por la Constitución de 1980, la intervención estatal de los años noventa y del primer decenio del dos mil se focaliza en asegurar una mayor igualdad de oportunidades tanto en los resultados como en el proceso educativo. Para Falabella (2015), los cuatro gobiernos de centroizquierda (1990-2010), compensaron la segregación social que reflejaba el sistema educacional del país otorgando subvenciones e incentivos según los resultados en las pruebas estandarizadas. De esta manera, se consolida un discurso ecléctico que considera al Estado y el mercado como complementarios en la formación de capital humano capaz de responder a las demandas de una economía y sociedad globalizada. Si bien la crisis que genera la inequidad y falta de regulación del sistema fue cuestionada por el movimiento de estudiantes secundarios ${ }^{2}$ del 2006, se elabora una nueva gestión pública propia de un Estado supervigilante que, conservando la misma lógica, evalúa, inspecciona y sanciona las fallas del mercado otorgando protección al consumidor.

A nivel del cuerpo de profesores, la aplicación de este paradigma económico en la educación pública nacional generó una flexibilización en las condiciones laborales de los docentes durante los años ochenta (Cox, 2006; Núñez, 2015). El cambio de empleador, ya sea el traspaso a un sostenedor municipal o privado, implicó que los profesores perdieran su condición de empleados públicos, lo que afectó sus ingresos y el desarrollo de su carrera profesional. Además, considerado un agente capaz de perturbar el orden nacional, las políticas implementadas por la dictadura militar en educación superior desvalorizaron el rol docente y durante algunos años no se reconoció su carácter universitario. Aunque el Estatuto docente elaborado durante los años noventa, ley n. 19.070 (1991) y ley n. 19.410 (1995), permitieron reparar el daño profesional causado a los profesores (remuneraciones, jornadas de trabajo, perfeccionamiento, pasantías, etc.), aparece un nuevo concepto de carrera docente cuyos ejes son: evaluación, desempeño y remuneración (ley n. 20.903). Siguiendo los lineamentos de la nueva política pública, el saber pedagógico del docente queda expuesto a la tensión que provocan el mercado y las intervenciones del Estado.

\section{PROBLEMÁTICA}

En este contexto, la experiencia acumulada por los docentes en el ejercicio de la docencia en realidades complejas requiere ser explorada, con el propósito de comprender cómo los docentes experimentaron las transformaciones del sistema educativo bajo el régimen autoritario con un impacto profundo en el financiamiento y la gestión del sistema escolar instalado a partir de 1973 y las rupturas y continuidades del retorno a la democracia en 1990 (Cox,2003). Pues poco sabemos desde las propias voces de los profesores sobre cómo interpretaron y sortearon las prescripciones implícitas o explicitas en su quehacer cotidiano y sobre cómo estas experiencias participan en la construcción de la identidad profesional docente (Ávalos, 2013) de quienes terminen este ciclo laboral.

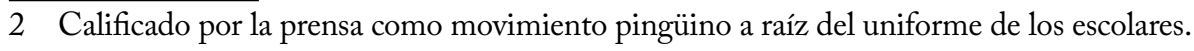


Estimamos, tal como lo advierte Sisto (2012), que lejos de ser figuras pasivas, los docentes experimentan formas de resistencia a las identidades individualizantes que se desprenden desde el nuevo management público. Entonces, el sentido ético que regula las acciones en el trabajo público impulsa prácticas de evasión y de resistencia a las políticas de gestión mediante resultados (Fardella y Sisto, 2015). Resulta entonces relevante explorar estas tensiones a partir las construcciones significativas de sus protagonistas. A su vez, ampliar la mirada hacia tensiones internas entre las representaciones identitarias de la profesión y las creencias, prácticas docentes que se despliegan en la trayectoria profesional, permite tomar distancia del modelo del "buen profesor", de las "buenas prácticas" y del "talento pedagógico" (Fuentes, Valdés y Campos, 2013) para explorar la práctica ordinaria compleja y paradojal a luz de su contexto.

Nuestra propuesta no pretende caracterizar ni la memoria colectiva ni individual de los docentes, como lo han hecho otros estudios de carácter histórico (Donoso, 2013; Polomer,2016), sino más bien busca comprender la perspectiva particular de docentes que culminan su carrera profesional. En consecuencia, el objetivo de la presente investigación es explorar la experiencia subjetiva de docentes en fin de carrera profesional, abordando dos momentos históricos en los que ejercieron: la dictadura y el regreso de la democracia.

\section{MATERIALES Y MÉTODO}

Esta investigación es de tipo cualitativa-interpretativa (Geertz, 2008), pues apunta a la construcción de significados a través de la interpretación y la comprensión de fenómenos. Para aproximarnos a la experiencia significativas de las docentes se optó por el método biográfico (Bolívar, Domingo y Fernández, 2001). La muestra se constituye de 5 profesoras de entre 60 y 65 años, que iniciaron su carrera entre 1974 y 1980 . Todas ellas culminan este ciclo laboral en la región del Maule, Chile. Dos de ellas se encuentran en retiro, mientras que las otras tres se proyectan un par de años más en sus lugares de trabajo (Tabla 1). Para la recogida

Tabla 1 - Caracterización de las profesoras participantes.

\begin{tabular}{c|c|c|c|c|c}
\hline $\begin{array}{c}\text { Código } \\
\text { participante }\end{array}$ & Formación & $\begin{array}{c}\text { Inicio en la } \\
\text { docencia }\end{array}$ & $\begin{array}{c}\text { Tipos de } \\
\text { establecimiento }\end{array}$ & Actividad & $\begin{array}{c}\text { Ultimo } \\
\text { establecimiento } \\
\text { de trabajo }\end{array}$ \\
\hline P1 & $\begin{array}{c}\text { Educación general básica } \\
\text { Religión y orientación }\end{array}$ & 1979 & Urbano & En ejercicio & Privado \\
\hline P2 & $\begin{array}{c}\text { Educación básica } \\
\text { Educación diferencial }\end{array}$ & 1974 & Rural & Jubilada & Municipal \\
\hline P3 & Educación física & 1979 & Urbano & En ejercicio & Municipal \\
\hline P4 & $\begin{array}{c}\text { Historia, geografía y } \\
\text { ciencias sociales }\end{array}$ & 1980 & Urbano y rural & En ejercicio & Municipal \\
\hline P5 & Educación general básica & 1974 & Urbano y rural & Jubilada & Municipal \\
\hline
\end{tabular}

Fuente: base de datos de investigación. 
de datos se entrevistó individualmente en tres y dos ocasiones a cada una de las participantes. Cada entrevista duró aproximadamente 70 minutos, fue grabada y transcrita integralmente. Los datos se recogieron entre noviembre de 2017 y febrero de 2018. Los resultados de este estudio fueron sometidos a la discusión entre las participantes, mediante la estrategia de grupo focal, durante el mes julio de 2018.

En cuanto a las consideraciones éticas de esta investigación, las participantes accedieron y firmaron un consentimiento informado al inicio de la investigación. En este documento, los investigadores, se comprometieron a proteger los datos personales y a respetar el relato de las profesoras, sin insistir en episodios sensibles o dolorosos. La discusión a la que fueron sometidos los resultados se enmarca también dentro de estas consideraciones, por cuanto se estima que los participantes tienen el derecho de conocer la manera en que los investigadores interpretan sus experiencias narradas.

Para el tratamiento de los datos se utilizó el método del análisis de contenido preconizado por la teoría fundamentada (Glaser y Strauss, 2017). El análisis fue de tipo inductivo y realizado bajo la asistencia del programa Nvivo $11^{\circledR}$. Se inició con una codificación abierta aplicando conceptos que se ajustan a los datos empíricos. Para llevar a cabo este proceso de etiquetaje, se reunieron las entrevistas por caso, estableciendo como caso cada una de profesoras participantes. Por lo tanto, los códigos no son necesariamente los mismos de un caso a otro. En una segunda etapa, se construyeron categorías temáticas, mediante una codificación axial (San Martín, 2014), lo que permitió reconstruir relatos con los aspectos significativos levantados por la profesora en su narración biográfica.

\section{RESULTADOS}

A continuación, se presentan en la Tabla 2 las categorías y los códigos que emergen del trabajo de codificación de cada una de las profesoras participantes del estudio.

En esta sección no se expondrán los resultados desde una lógica de representatividad de referencias codificadas, sino que desde la posibilidad de reconstruir un relato con los aspectos significativos levantados por las profesoras en su narración biográfica y generar un diálogo entre ellos.

Las profesoras entrevistadas viven actualmente en la región del Maule y ejercieron gran parte de su carrera profesional en esta misma región. Todas ellas comenzaron a trabajar como docentes siendo muy jóvenes, aproximadamente a los veinte años de edad, y debutaron en la profesión como reemplazantes. Las profesoras 1, 3 y 5 trabajaron en diferentes establecimientos, rurales, urbanos, municipales y privados subvencionados por el Estado. Mientras que las profesoras 2 y 4 permanecieron durante casi toda su carrera en un mismo establecimiento educacional público. Si bien, tres de ellas encontraron tempranamente una estabilidad laboral, todas ellas estuvieron sujetas a variaciones contractuales que variaban su renta. Cuatro de las cinco profesoras trabajaron durante varios años en más de un establecimiento escolar para poder complementar sus ingresos. 
Tabla 2 - Resultados análisis entrevistas.

\begin{tabular}{|c|c|c|}
\hline Profesora & Categoría & Códigos \\
\hline \multirow[t]{2}{*}{ Profesora 1} & Dictadura & $\begin{array}{c}\text { Sin libertad pedagógica, Vivir con miedo, Solidaridad } \\
\text { riesgosa, Persecución, Obligaciones, Resistencias, Silencio, } \\
\text { Engaño de la municipalización, Agrupaciones clandestinas, } \\
\text { Traspaso a AFP, Responsabilidad personal. }\end{array}$ \\
\hline & Gerencialismo & $\begin{array}{l}\text { Uso de recursos públicos, Lucro, No pagaban, } \\
\text { Resistencias, Inestabilidad laboral, Mecanización de } \\
\text { la escuela, Etiquetaje, Pérdida de la autonomía. }\end{array}$ \\
\hline \multirow[b]{2}{*}{ Profesora 2} & Dictadura & $\begin{array}{l}\text { Resistencias, Cambio régimen de pensiones, Obligaciones, } \\
\text { Engaño, Error, Lugar protegido, Perdida de beneficios. }\end{array}$ \\
\hline & $\begin{array}{l}\text { Ruptura de los } \\
\text { nuevos tiempos }\end{array}$ & $\begin{array}{l}\text { Organización de la enseñanza, Resistencias, Constitución } \\
\text { de equipos, Burocratización, Integración escolar, Recursos } \\
\text { materiales, Asistencia escolar, Mejora de las condiciones salariales, } \\
\text { Reconocimiento perfeccionamientos, Apoderados demandantes. }\end{array}$ \\
\hline \multirow{4}{*}{ Profesora 3} & $\begin{array}{l}\text { Compromiso } \\
\text { con el trabajo }\end{array}$ & $\begin{array}{l}\text { Ejercer en contextos vulnerables, Entregar cariño, } \\
\text { Escuelas sin recursos, Falta de compromiso de los } \\
\text { nuevos docentes, Gremialismo docente debilitado. }\end{array}$ \\
\hline & $\begin{array}{l}\text { Equilibrio } \\
\text { trabajo-vida }\end{array}$ & Condiciones de vida limitada, Actividades domésticas. \\
\hline & $\begin{array}{l}\text { Gestión arbitraria de } \\
\text { los establecimientos }\end{array}$ & $\begin{array}{l}\text { Cultura patronal, Contratación arbitraria, Lucro, } \\
\text { Malas prácticas, Proyectos que se desvanecen. }\end{array}$ \\
\hline & Jubilación Incierta & $\begin{array}{l}\text { Deuda histórica, Nadie quiere pagar, Futuro incierto, } \\
\text { Régimen de pensiones, Engaño, Obligaciones. }\end{array}$ \\
\hline \multirow{4}{*}{ Profesora 4} & Dictadura & $\begin{array}{l}\text { Libertad pedagógica, Educación en democracia, Imposiciones, } \\
\text { Resistencias, Organizaciones clandestinas, Desconfianza, } \\
\text { Intervención, Colegio de profesores, Miedo, Cambio régimen de } \\
\text { pensiones, Obligaciones, Información controlada, Deuda histórica. }\end{array}$ \\
\hline & Gremialismo & Luchas, Abusos, Demandas, Nuevas generaciones docentes. \\
\hline & $\begin{array}{c}\text { Dualidad } \\
\text { administrativa }\end{array}$ & Relación con el empleador, Dirección de la escuela. \\
\hline & $\begin{array}{l}\text { Sistema } \\
\text { competitivo }\end{array}$ & Pruebas estandarizadas, Evaluación docente. \\
\hline \multirow{4}{*}{ Profesora 5} & $\begin{array}{l}\text { Trabajar en } \\
\text { dictadura }\end{array}$ & $\begin{array}{l}\text { Omnipresencia de los militares, Miedo, Desconfianza, } \\
\text { Silencio, Imposiciones, Engaño de la deuda histórica, Miedos } \\
\text { ante los cambios, Nadie quiere pagar la deuda histórica. }\end{array}$ \\
\hline & $\begin{array}{c}\text { Desconfianza ante } \\
\text { las autoridades }\end{array}$ & $\begin{array}{c}\text { Luchas de los profesores, Se sigue abusando, Gremio dividido, } \\
\text { Falta de transparencia, Rechazo profesional, Burocratización } \\
\text { de la escuela, Proyectos que quitan tiempo, Oficinas } \\
\text { de puertas cerradas, Subvención escolar. }\end{array}$ \\
\hline & $\begin{array}{l}\text { Contextos de } \\
\text { trabajo hostiles }\end{array}$ & $\begin{array}{c}\text { Condiciones de trabajo precarias, Bajo nivel educacional, Pobreza } \\
\text { en la escuela, Sobrecarga de trabajo, Contextos vulnerables. }\end{array}$ \\
\hline & Nuevos Tiempos & $\begin{array}{l}\text { Cultura de resultados, SIMCE, Falta de } \\
\text { autonomía, Subvención preferencial, } \\
\text { Comodidad, Asesorías externas. }\end{array}$ \\
\hline
\end{tabular}

Fuente: base de datos de investigación. 
Resulta relevante destacar un aspecto característico de nuestra muestra de participantes: su género. Las docentes al evocar los inicios de su carrera abordaron las funciones sociales tradicionalmente atribuidas a la mujer bajo el contexto de una dictadura social y política patriarcal.

Las profesoras 2 y 5 describen los inicios de su carrera como un periodo de arduo trabajo profesional y personal, pues no solo se introducían al mundo laboral y a una profesión, sino que también se iniciaban en la maternidad. A las actividades propias del trabajo docente tanto dentro como fuera del aula y del tiempo de trabajo contractual, se sumaban el cuidado de los hijos, el apoyo de las tareas escolares, las actividades domésticas. Obligaciones que describen como propias de su rol femenino. En sus relatos es posible observar como un elemento transversal la ausencia de la figura masculina en estos episodios de sus vidas, así como también en sus discursos educativos, pues las profesoras asociaban las tareas de apoyo escolar y de educación en general a la madre. Esta mirada se sostiene a la hora de comparar su situación de antaño con la de las nuevas generaciones de profesoras que tienen al alcance tecnologías que le permiten llevar a cabo tareas domésticas. Por el contrario, la profesora 4, señala que en sus inicios profesionales sintió más bien que debió encontrar un lugar en un espacio dominado por los hombres, en donde las decisiones y las responsabilidades no eran confiadas a mujeres y menos a mujeres jóvenes. Destaca que lleva más de treinta años trabajando en un establecimiento de educación secundaria público selectivo, y que no ha tenido una mujer como directora ni en dictadura ni en democracia.

\section{... EL EJERCICIO DE LA DOCENCIA EN DICTADURA}

Los acontecimientos ocurridos durante la dictadura militar estarían al origen de importantes cambios en la labor docente que conocieron por la tradición familiar y social cuando iniciaron sus carreras. La dictadura como escenario significativo en la historia profesional está presente en los relatos de las profesoras entrevistadas.

La profesora 1 se refiere al ejercicio de la docencia en dictadura como un período marcado por el miedo. Lo describe como un sentimiento permanente y compartido por la comunidad educativa que motivó solidaridades, desconfianzas y también decisiones que hoy ella considera desafortunadas. La amenaza latente de ser perseguido o detenido por las autoridades instituyó en sus entornos laborales la desconfianza y una suerte de secretismo ideológico, que limitaba la discusión en torno a la contingencia política tanto con los pares como con los alumnos. Sobre este mismo punto, la profesora 4 hace hincapié en los cambios que produjo este momento histórico en la libertad de enseñanza de los profesores. Ella percibió la forma en como la política del momento influyó directamente en el currículo y en la enseñanza en las escuelas.

Durante mucho tiempo solo se trabajaba la historia de Chile hasta el año 1952. En esos tiempos era así y, por lo tanto, si te preguntaban sobre la realidad que se estaba viviendo, que no estaba dentro del currículo, uno tenía que tratar de desarrollar una respuesta frente a lo que se estaba viviendo y era muy difícil 
porque también había mucha presión de por medio, mucho resguardo frente a lo que uno debía trabajar. (P4, Categoría: Dictadura — Libertad pedagógica)

Experiencias similares a las anteriores vivió la profesora 5, quien tempranamente se insertó en una cultura profesional caracterizada por el miedo, la desconfianza y el silencio. Señala que la omnipresencia militar y hasta las más mínimas imposiciones vestimentarias, la incitaban a adoptar una actitud cautelosa frente a sus colegas y a las autoridades locales.

En el 74, estábamos recién después del golpe, entonces uno tenía que andar... como se dice "andar pisando huevos", porque cualquier cosa le podía a uno causar el despido de su trabajo. (P5, Categoría: Dictadura - Miedo)

La profesora 4, describe igualmente un clima de desconfianza entre colegas en el mismo establecimiento educativo donde trabajaba:

Fue difícil para nosotros como profesionales de la educación trabajar en ese contexto. Internamente también, porque todo lo que pasaba en el país también pasaba en los espacios más reducidos, más pequeños, como, por ejemplo, la desconfianza, porque, así como había a nivel del país grupos que se infiltraban para entregar información, también existía la desconfianza... porque de repente había personas que no eran profesionales de la educación pero que llegaban a un cargo determinado. Entonces inmediatamente era posible darse cuenta de que esa persona venía con una función específica. (P4, Categoría: Dictadura Desconfianza)

A pesar del temor y la desconfianza predominante, la profesora 1, rescata la solidaridad de sus apoderados ante ese contexto amenazante.

En ese tiempo que fue cuando murieron estos profesores... Parada, en Santiago. ${ }^{3}$ Yo estaba haciendo clases en Santiago y los apoderados me iban a esperar a la mi$\mathrm{cro}^{4}$ para que yo pudiera llegar a mi trabajo. (P1, Categoría: Dictadura - Miedo)

Ella interpreta esos gestos como una demostración de la valoración de su trabajo, lo que hoy, afirma, la reconforta a la hora de recordar momentos dolorosos.

Dentro de este contexto autoritario, las profesoras 1, 2 y 4 declaran con orgullo haber encontrado formas de resistir de alguna manera al poder de facto en su vida profesional. Una de ellas era la negativa a desfilar en la ciudad o asistir a eventos públicos con la presencia de autoridades militares:

3 Tal como lo advierte Candina Polomer (2016), el informe Retting de 1991 señala que 58 profesores fueron ejecutados y 45 detenidos desaparecidos. Entre ellos se incluye el secuestro y asesinato del profesor Manuel Guerrero, junto con el sociólogo José Manuel Parada y el pintor Santiago Nattino, por parte de la Dirección de Comunicaciones de Carabineros, DICOMCAR el 27 de marzo de 1985.

4 Bus de transporte público. 
Mi director decía — "viene el señor Pinochet a Talca”, y nos acarreaban para Talca. Yo decía: "yo no voy a ir a Talca, no me gustan los grupos grandes". Me respondían - "no, porque si no, va a tener problemas" - "yo asumo, pero yo no voy a ir a esas concentraciones para ir aplaudir". Más encima que no estaba de acuerdo. Así que no, no, no más. Nunca me pasó nada, alguien podría haberme acusado y decir "no va, no le gusta este señor" pero no, nunca tuve ese problema de que me persiguieran, o algo. (P2, Categoría: Dictadura — Resistencias)

Así como también se manifiesta en la participación en organizaciones gremiales de oposición, en el caso de las profesoras 1 y 4 . Estas organizaciones se presentaban como una alternativa al Colegio de profesores, en el que entonces las profesoras entrevistadas no se depositaban toda su confianza. A través de esta asociación se organizaba la lucha contra el régimen dictatorial de entonces.

Se constituyó esta organización que era la AGECH, Asociación Gremial de Educadores de Chile, de alguna forma, con cierta clandestinidad, porque no estaba permitido dentro del periodo de la dictadura que funcionara. Por lo tanto, eran grupos reducidos y muy ocultamente se hacían reuniones para poder organizar y preparar las instancias de lucha dentro del profesorado. (P4, Categoría: Dictadura - Resistencias)

Las profesoras contrastan estas formas de resistencia con la pasividad con la acataron, sin cuestionar las disposiciones de las autoridades de la época. Las cinco profesoras concuerdan en que fue un desacierto aceptar el traspaso del sistema de reparta administrado por la Caja Nacional de Empleados Públicos y Periodistas al entonces nuevo sistema de Administración de Fondo de Pensiones (AFP) ${ }^{5}$ de ahorro y capitalización individual.

Yo no sé qué me pasó. Nunca averigüé nada, nada, nada al respecto. Asumí que esto era una obligación. Y en el momento en que firmé me dijeron "o firma o se va”. Como no me quería ir, firmé. Entonces como que no había más alternativas. (P2, Categoría: Dictadura - Traspaso AFP)

Es posible observar en las narraciones biográficas de las docentes que este evento tiene una repercusión en su actual situación de jubilación. Lo que hace que en sus relatos se establezca de manera casi general un vínculo entre sus primeros años de trabajo con el fin de su carrera profesional.

5 El 4 de noviembre de 1980, el gobierno militar decreta la privatización de la administración de pensiones, disminuyendo drásticamente el rol del Estado en el sector previsional. El 11 de mayo de 1981, once AFP iniciaron sus actividades haciendo prevalecer al ahorro personal para la jubilación y la rentabilidad, a través del cobro de comisiones e inversiones en el sector privado (Menanteau-Horta, 2017). 


\section{... EJERCER EN DEMOCRACIA}

Las elecciones presidenciales de 1989 ponen fin a la dictadura militar de Augusto Pinochet. La profesora 4 describe este acontecimiento como un momento de gran alegría, porque a, su vez, permitirá incorporar prácticas democráticas en el liceo donde ha trabajado durante casi toda su vida profesional.

El primer Centro de Alumnos que se eligió fue, a partir del año 89, que fue el primer presidente elegido, fue un alumno de mi curso... y también ellos mismos tuvieron la posibilidad de elegir a sus profesores asesores, porque antes de eso, eran designados por el director. El centro alumnos y los profesores asesores eran designados también por el director. Por lo tanto, todo estaba dentro del mismo contexto, lo que significaba entonces abrir las opciones. Fue a partir del año 89 con el plebiscito del 88 del Sí y el No, que se abrieron todos los espacios en todos los niveles también. (P4, Categoría: Dictadura — Libertad Pedagógica)

Progresivamente, estima esta misma profesora, los alumnos y los demás profesores comenzaron a hacer uso de la libertad pedagógica, de expresión, de asociación profesional y de los espacios de desarrollo profesional y educativo que traía el retorno de la democracia.

Las profesoras 4 y 5 hacen valoran instancias de aprendizaje en las que pudieron participar, tales como formaciones y estancias en el extranjero que las posicionaron como profesionales de referencia antes sus pares. No obstante, lamentan el desaprovechamiento de recursos invertidos en ellas, pues prontamente, las oportunidades de compartir o difundir lo aprendido con sus colegas se fueron reduciendo hasta diluirse en el tiempo y con la llegada, en los años 2000, de los servicios externos y privados de Asesoría Técnica Educativa (ATE). ${ }^{6}$

Estos talleres de reflexión que había antes eran muy buenos porque uno no necesariamente le tiene que pagar a un ATE, llamémoslo con los nombres de ahora. A veces, en los mismos colegios hay gente muy capacitada para hacer talleres, pero ahora, no. (P5, Categoría: Nuevos tiempos - Asesorías externas)

Los establecimientos públicos siguieron dependiendo de los municipios, ya no gobernados por alcaldes designados, sino que, elegidos por el voto ciudadano, lo que implicaba disparidad ideológica de una comuna a otra. Pero esencialmente, significaba que el cuerpo docente se encontraba frente a una variedad de empleadores con quienes negociar. Las profesoras participantes describen una permanente tensión con el empleador.

6 Las ATE son organismos que prestan servicios de apoyo a establecimientos educacionales. Aunque son externas al Ministerio de Educación, cuentan con su certificación para asesorar a los centros educativos en la implementación del Plan de Mejoramiento Educativo (PME). Se financian con los recursos otorgados mediante la Subvención Escolar Preferencial (SEP). 
El alcalde anterior nada, cero, él siempre se negó, nosotros éramos un lastre para él, públicamente él lo manifestó en muchas demandas que tuvimos tanto los estudiantes, como los profesores. Incluso hay una frase que él no la puede negar porque la dijo: "que los estudiantes de la educación pública eran unos muertos de hambre”. (P4, Categoría: Dualidad administrativa - Relación con el empleador)

Las profesoras 1, 3, 4 y 5 evalúan negativamente la gestión municipal de los establecimientos educativos. Todas ellas consideran que las entidades comunales privilegian intereses económicos y políticos por sobre los intereses educativos de los alumnos y las condiciones de trabajo de los profesores.

Nosotros quedamos en una dualidad, por una parte, éramos del Ministerio, dependíamos curricularmente del Ministerio, pero económica y administrativamente de la municipalidad. La municipalidad no toma decisiones pensando en el beneficio de los estudiantes, pedagógica o curricularmente, toma decisiones económicas. Cuando nosotros planteábamos proyectos... si no es rentable económicamente para la municipalidad, lo rechazaban. Muchas veces nosotros planteábamos ir disminuyendo la cantidad de alumnos por curso en beneficio del aprendizaje, " Nol, porque si la sala tiene capacidad para 45 y la ley permite que tenga $45 \ldots$... Y se llena con 45 alumnos la sala. Si hay profesores que pueden dedicar, por ejemplo, 15 horas de aula, y pueden hacer la otras 15 en otro proyecto, en otra actividad, no sé..., “№! porque no es rentable”. Entonces, los mandan a trabajar a otra escuela. (P4, Categoría: Dualidad administrativa Dirección de la escuela)

Igualmente, las profesoras señalan que la administración municipal de los establecimientos generó inestabilidad laboral. Para la profesora 3 esta situación fue siempre un motor de lucha para el gremio docente. Lucha en la que ella se implicó personalmente, pues pasó gran parte de su trayectoria profesional sin contar con un contrato indefinido. La profesora 3 manifiesta una mirada más bien pesimista sobre ciertos aspectos de la gestión de los establecimientos educativos. En esta esfera de poder se encontrarían instalados procedimientos cuestionables relativos a la contratación de profesores y cargos directivos, al manejo de los recursos y la toma de decisiones. Para ella, estos procedimientos son arbitrarios y pondrían de manifiesto una cultura patronal en el seno de la gestión de los establecimientos de subvención pública, teniendo como consecuencia, una gestión que reduce la figura del profesor a la de empleados. Para la docente, son las permanentes luchas impulsadas por el gremio de profesores las que han permitido avanzar en la valoración del trabajo y la búsqueda de la justicia ante abusos de los empleadores. No obstante, la docente lamenta el debilitamiento de estos organismos colegiados debido al desinterés de las nuevas generaciones de profesores, a quienes califica como una generación individualista y materialista. Así los nuevos docentes se habrían deprendido de la función de social y de la solidaridad gremial que habría caracterizado la profesión.

La juventud de ahora no trabaja si no es por dinero. Yo no sé hasta qué punto es bueno, porque nosotros no, no éramos así. Pero la juventud de ahora, la veo, yo he trabajo 
con gente que está recién ingresando a la educación, y ellos no van a campeonatos los sábados o los domingos porque no está dentro de su horario. (P3, Categoría Compromiso con el trabajo - Falta de compromiso de los nuevos docentes)

Desde la perspectiva de las profesoras, la desconcentración de la administración educativa instaló prácticas enfocadas en la rendición de cuentas. La profesora 1 explica que:

Para los directores era mucho más beneficioso que, desde el DAEM dijeran "ese material, el director lo entregó impecable", porque un material que se usa se gasta se desgasta, no es que se vayan a comer el teclado, evidentemente, se van a borrar las letras porque está usado ¿cierto? Pero para ellos era más importante responder a estas autoridades como un buen profesional en el sentido que había cuidado las cosas. Por eso no lo usaban. (P1, Categoría: Gerencialismo - Uso de recursos)

Esto es palpable para ellas en la obsesión por los resultados en las evaluaciones nacionales. Con la consolidación del SIMCE, las escuelas y los equipos docentes habrían experimentado una gran presión social y política. La profesora 5, que ya está jubilada, se queda con el recuerdo de una escuela organizada en función de los resultados de las evaluaciones SIMCE, tanto por el prestigio escolar y la evaluación profesional como por los incentivos monetarios que un buen rendimiento otorga.

Eso que dicen: "nosotros no trabajamos para el SIMCE" eso no es cierto, porque al colegio que uno vaya, se ve que todo gira en torno al SIMCE, sobre todo en cuarto año. Para las postulaciones a los proyectos se ve cómo uno fue evaluado por el SIMCE. (P5, Categoría: Cultura de resultados - SIMCE)

La profesora 5 percibe una focalización en los resultados que limita las posibilidades educativas de los niños, reduciendo el trabajo académico a la preparación de pruebas estandarizadas. De igual manera, para la profesora 4 la educación chilena apunta solamente al cumplimiento de exigencias externas, que tienen una definición reducida del éxito académico. En consecuencia, se estarían limitando así las múltiples posibilidades de desarrollo de los jóvenes.

Nosotros acá en este colegio, como se le considera un liceo emblemático, es el liceo que mayormente le otorga a la ciudad los mejores puntajes, además de que es municipalizado, le otorga los buenos puntajes. Entonces se nos va midiendo de acuerdo con eso, entonces todos te van exigiendo, y llega un momento en el que hay que trabajar todo, porque los estudiantes en cuarto medio tienen que haber trabajado todo: deben tener buenos puntajes, tenemos que subir el promedio del liceo. Finalmente, ese sistema evita que tú puedas desarrollar muchas otras áreas y muchos otros trabajos. (P4, Categoría: Sistema Competitivo — Pruebas estandarizadas)

A partir de esta nueva época que vivió el país, la profesora 2 percibió en sus últimos años de trabajo una progresiva burocratización de la labor docente. Esta 
profesora resiente una insistente demanda de formalización, en lugar de apoyo profesional, por parte de las autoridades de la educación.

Llegaba de la secretaría ministerial, las personas y nos pedían a cada uno un par de carpetas, no las pedían todas, pero bueno uno se asustaba de no tenerlas todas. Ahí ellos anotaban: "no, muy bien el trabajo, excelente" ¿Por qué? Porque estaban todos los papeles, llenitos ¿Leerían toda esa cantidad de papeles por niño? Yo tengo mis dudas. Entonces en ese sentido, había como supervisión y había control más que ayuda. (P2, Categoría: Ruptura ante los nuevos tiempos - Burocratización)

Estas situaciones las contrasta con la valoración de su trabajo que sentía por el director de la escuela donde atendió a alumnos con necesidades educativas especiales durante toda su carrera. Ella misma confiaba en la calidad de su trabajo y recuerda que gozaba de márgenes de autonomía que fue perdiendo con las nuevas reformas en torno a la integración escolar.

Eso fue una ayuda grande, porque (el director) siempre valoró el trabajo de las profesoras diferenciales, no así los profesores en algunos momentos, pero si el director, evitar repitencias, ayudar a los niños a que salieran adelante, todo eso lo valoraba mucho. (P2, Categoría: Autonomía profesional)

\section{... EL RETIRO DE LA PROFESIÓN DOCENTE}

Todas las profesoras entrevistadas manifestaron su inseguridad ante la jubilación, tanto aquellas que ya se encuentran retiradas como quienes se aprontan a abandonar la profesión. La profesora 3 relata la tranquilidad que le proporcionó obtener un contrato indefinido con una municipalidad del Maule, ya que con esto no solo culminaban años de incertidumbre laboral, sino que también le aseguraba un incremento en las rentas de su jubilación e incentivos al retiro. Sin embargo, las condiciones en las que podría jubilar siguen siendo precarias y limitan sus proyectos personales.

No puedo jubilar porque tengo tres hijos en la Universidad. Si yo me retirará, en estos momentos estaría con un sueldo de $\$ 200.000$ pesos, con los que no alcanza a pagar ni una universidad. Y después ¿de qué vivo? Entones ese es un gran problema. Muchos evitamos jubilarnos, porque tenemos responsabilidades. (P3, Categoría: Jubilación incierta — Futuro incierto)

Ante este contexto el hecho de sentirse capacitada para seguir trabajando, le proporciona cierta tranquilidad para enfrentar esta nueva etapa. Para la profesora 3 el origen de esta precaria situación se encontraría en dos sucesos ocurridos al inicio de su carrera profesional: el transito engañoso y forzado desde la Caja de Previsión a las AFP y el traslado de las escuelas y liceo públicos al municipio. 
Nos dijeron que iba a hacer mucho mejor, que iba a mejorar la calidad de vida, que íbamos a tener una mejor jubilación, yo estaba egresando en ese momento, y obvio que uno quiere todo eso, bueno, pero con el paso del tiempo uno se dio cuenta que no es así, pero, ya estaba hecho. (P3, Categoría: Jubilación incierta - Régimen de pensiones - Engaño)

El primer acontecimiento habría pauperizado las rentas de la jubilación, mientras que el segundo, estaría asociado a compromisos aún no cumplidos por el Estado chileno. Las profesoras entrevistadas consideran que el reconocimiento de la Deuda histórica del Estado chileno ${ }^{7}$ permitiría la mejorar de las condiciones económicas del retiro laboral. En sus relatos es patente la frustración antes las pocas posibilidades de ver realizado el pago de dicha deuda.

Yo creo que ya ha muerto tanta gente y se fueron luchando por la deuda histórica. Pienso que eso es lo que están esperando, a lo mejor, que no muramos todos. (P3, Categoría: Jubilación incierta - Deuda histórica - Nadie quiere pagar)

La sensación de engaño es compartida por todas las profesoras debido a la presión que sintieron para cambiarse al sistema de AFP al inicio de su carrera. Al respecto, la professora 1 señala:

Nunca en el colegio nos dijeron si usted quiere firme. Era: "o firma o firma". Nunca supimos que había otra alternativa. Entonces todos firmamos. (P1, Categoría: Dictadura - Traspaso a AFP)

La profesora 2 reflexiona sobre las consecuencias generadas por sus primeros años de ejercicio laboral, debido al momento histórico que se vivía. Consecuencias patentes en la situación actual de muchos profesores chilenos. Cargada de emociones punzantes analiza aquella época en la que siente haber sido engañada y forzada a cambiar de régimen de cotizaciones previsionales, hecho que hoy se encuentra el origen de la precariedad económica con la que vive su jubilación.

Yo no quería cambiarme, llevamos ocho años trabajando allá en el otro sistema. Yo le dije que yo me quedaba aquí no más con esto. "Señora, usted va a tener problemas, tiene que cambiarse" [...] Fue tanto que, entre el que director que molestaba y los vendedores que venían a vender la pomada... hasta que " $¡ Y a ! . .$. Habrá que cambiarse”. Y en la escuela nos cambiamos todos. (P2, Categoría: Dictadura - Régimen de pensiones)

7 De acuerdo con lo señalado por el Colegio de Profesores: "La Deuda Histórica de los profesores se originó por el incumplimiento de la ley n. 3.551 de 1981, que dispuso un reajuste del sueldo base al sector público, estableciendo en su artículo 40 una "asignación especial" no imponible para el personal docente dependiente del Ministerio de Educación. Como resultado de la municipalización impuesta a partir del año 1981, la mayoría de los profesores no alcanzaron a recibir el 100\% de la asignación, pues al ser traspasados al sector municipal, los nuevos empleadores desconocieron los derechos adquiridos por los profesores" (Colegio de Profesores de Chile, 2018). 
Por otro lado, está latente el sentimiento de injusticia, ante la falta de reconocimiento de deudas adquiridas por el Estado chileno en los años 1980 que no han sido reconocidas y cumplidas desde el regreso a la democracia. En un afán de justicia la profesora se moviliza y lidera, con el apoyo de un abogado, un grupo de docentes en retiro que reclaman el pago de la Deuda histórica.

Nosotros tenemos la esperanza de que en algún momento se nos pague, porque es algo que se nos debe, no es algo que estemos pidiendo así porque se nos ocurre. Es algo que nos prometieron y no se cumplió. Eso fue en el gobierno del señor Pinochet y no se cumplió, a las municipalidades no les llegaron los dineros. (P2, Categoría: Dictadura - Deuda histórica)

Esta situación la llevó a la profesora 2 a movilizarse de manera personal y a tomar distancia del Colegio de profesores, pues este ha logrado conseguir avances en esta materia. Esta gestión independiente de la deuda histórica no habría sido bien percibida por este organismo, que habría acusado a estas agrupaciones de fraudulentas.

Finalmente, en los relatos de las profesoras es patente el sentimiento de no haber recibido por parte de las autoridades, la justa valoración de todo el trabajo realizado y la confirmación de una jubilación económicamente modesta, dejan decepción y precariedad como los resabios del retiro profesional.

\section{DISCUSIÓN Y CONCLUSIONES}

El objetivo de este artículo fue de estudiar las experiencias de la vida profesional de cinco docentes chilenas que se encuentran en fin de su carrera. El propósito fue el de comprender los aspectos significativos que marcaron el ejercicio de la profesión durante la dictadura (1973-1990) y la posterior democracia iniciada en 1990.

Sin intentar reconstruir una memoria colectiva, ni generalizar la experiencia docente, se persiguió más bien comprender desde una mirada retrospectiva particular, el presente y el futuro de las profesoras entrevistadas. Tal como lo expone (Bolívar,2016) la narración biográfica nos proporcionó un marco metodológico para analizar aspectos esenciales de una profesión en el tiempo de una persona, ofreciendo trayectorias que hacen inteligibles la complejidad de la vida y de la acción humana y social en su contexto de trabajo.

A través de sus relatos biográficos podemos retener que la interpretación que las profesoras hacen de su experiencia está siempre conectada al contexto sociopolítico en el que ejercieron la labor docente. La dictadura militar condicionó la actitud profesional con la que debutaron en la profesión.

De acuerdo con Zurita (2017), los sistemas de vigilancia y la persecución política constituyeron, junto con la delación, uno de los principales mecanismos represión y violencia de la dictadura militar hacia el profesorado. La omnipresencia militar, las medidas de control y represión ejercidas por el Estado Chileno hacia la población las resintieron también las profesoras en sus espacios de trabajo cotidiano. Aunque ninguna de ellas señaló haber sido perseguida por el Estado chileno, el miedo de ser despedida o de ser detenida era latente y aparece como un componente de la cultura escolar. En la que debutaron como profesoras. En- 
tendiendo que en el periodo de inserción profesional es también un momento de primera socialización profesional (Marcelo García, 2009), las normas, valores y comportamientos adquiridos en esta etapa de su vida profesional son analizadas por las docentes como aspectos constituyentes de una identidad profesional pasiva. Retienen principalmente el traspaso poco cuestionado a las AFP en los primeros años de ejercicio, hecho que hoy concatenan con las condiciones desmedradas de la jubilación. Según el Colegio de Profesores de Chile (2014):

Actualmente los docentes están recibiendo, en promedio, una pensión entre $\$ 180.000$ y $\$ 200.000^{8}$; incluso hay casos en los que profesores y profesoras que, habiendo trabajado 30 años reciben pensiones de $\$ 120.000^{9}$, lo que representa menos del $25 \%$ del último sueldo recibido. Esto se debe especialmente al daño previsional generado por el sistema de Administradoras de Fondos de Pensiones (AFP) - que no afecta solo al profesorado - , pero también al escaso reconocimiento social y público que tiene el ejercicio docente, y a la falta de una carrera profesional que asegure remuneraciones y jubilaciones justas.

Los testimonios de las docentes entrevistadas ponen de manifiesto que las políticas neoliberales implantadas durante la dictadura, como la municipalización de los establecimientos escolares y el traspaso a las AFP, continuaron su curva de desarrollo luego del retorno a la democracia y no implican el reconocimiento de demandas que se desprenden de compromisos asumidos por el Estado chileno al inicio de su trayectoria profesional.

El desconocimiento hasta la fecha del reajuste prometido al momento de la municipalización (deuda histórica) y las escasas expectativas de los docentes jubilados constituyen parte de la identidad compartida por las docentes que participaron en las entrevistas. Las condiciones de vida precarizada que ofrece el retiro profesional son consideradas como rasgo distintivo de la generación actual de los docentes, no así de quienes se integran a la nueva carrera docente. Esta última trae para los profesores mejoras salariales y oportunidades de desarrollo institucional que ellas no conocieron. Se reconocen como profesoras engañadas por la dictadura y por la democracia. Las profesoras que ejercieron durante estos períodos experimentaron primero con amenazas del régimen omnímodo de los años 70 y 80, y luego, con la democracia, la alimentación de falsas esperanzas, e incluso indiferencia gubernamental y social de sus reivindicaciones en cuanto al pago de la deuda histórica y el incremento de sus pensiones de vejez.

Con la vuelta de la democracia, el miedo que despertaba el régimen autoritario y que limitó la actividad pedagógica, la libertad de expresión y la posibilidad de contestar abiertamente y cuestionar las políticas que se asentaban en el país, se desvanecía. Sin embargo, la administración de la oferta y la demanda educativa que se instaló oficialmente en los años 90 institucionalizó la libertad de enseñanza y junto con ello el control de la calidad del servicio y el incentivo al mérito individual de los profesores. Se desvincula la profesión de la concepción de servicio público

8 Equivalente a 264-294 dólares estadounidenses aproximado.

9 Equivalente a 176 dólares estadounidenses aproximado. 
para asociarse a la de management de resultados (Soto et al., 2016), se confirmaba de esta manera la posición de subordinación salarial de los docentes ante agentes municipales y privados despojados de la confianza del profesorado.

Cornejo (2006) afirma que dos enormes dificultades han presentado la municipalización de los establecimientos escolares, antes públicos dependientes del Ministerio de la cartera. Por una parte, gran parte del poder recae en los organismos "sostenedores" municipales y privadas y no guarda ninguna relación con sus capacidades técnicas que estos pueden tener. En su gran mayoría no cuentan con equipos técnicos pedagógicos que apoyen la toma de decisiones escolares privilegiando criterio de maximización de las ganancias y de eficiencia en las decisiones de su gestión. Los sostenedores no asumieron la estabilidad y el desarrollo de una trayectoria profesional. Las relaciones actuales son más bien tensas, pues las profesoras estiman que el desempeño de los sostenedores resulta ineficiente, a veces contraproducente, para las suplir las necesidades educacionales de los establecimientos y para establecer diálogos con el cuerpo docente.

Las relaciones con el empleador municipal son destacadas como complejas por cuanto se ha instalado una cultura gerencialista que entrega absoluto poder de decisión a los dirigentes municipales en lo que compete la situación laboral de los docentes y la gestión de los establecimientos. Procedimientos como la contratación, movilidad profesional de los docentes y el destino de los dineros estatales serían de la exclusiva responsabilidad de estos agentes, en quienes las profesoras no depositan su confianza. Si bien, tres de las profesoras entrevistadas gozaron tempranamente de estabilidad laboral, todas ellas estuvieron sujetas a variaciones contractuales e incluso en litigios con el empleador, pues año a año un cierto número de horas de trabajo no estaban aseguradas para las profesoras variando así su renta.

En consecuencia, el miedo a perder el trabajo en los primeros años de la profesión y las pocas expectativas que podía tener un profesor que fuera vinculado con la oposición al gobierno de facto, se modifica y es más tarde, en democracia y al fin de la profesión docente, miedo a no contar con un contrato de trabajo estable y con un número de horas significativas a ad-portas de la jubilación. Se perpetúa así la tensión entre los profesores y el empleador, ya sea municipal, ya sea privado.

Las profesoras entrevistadas evocan la condición de empleado público como aspecto de la tradición docente a la que ingresaron, pero no la que experimentaron durante su vida profesional. Supeditadas al control militar y luego al de los resultados, la identidad docente se construye en una permanente readaptación a las exigencias que emanan de figuras externas de las que desconfían. Si durante la dictadura militar la desconfianza predominaba en las relaciones laborales, la llegada de la democracia trajo consigo una cultura de trabajo centrada en el logro de resultados, estimulando la colaboración solo en este sentido, pero a cambio de reconocimiento individual. Los espacios de creación, de apoyo y de reflexión educativa quedan postergados a un segundo plano debido a la incesante búsqueda de mejores desempeños en las pruebas estandarizadas que les permitan justificar su labor profesional. Esta percepción coincide con la literatura que califica al rol del Estado como un ente evaluador mediante políticas de Rendición de Cuentas, tales como el SIMCE en tanto que mecanismos 
que intentan corregir las falencias del esquema mercantil implantado en dictadura (Parcerisa y Falabella, 2017).

Ante esta situación las profesoras lamentan la disgregación del cuerpo de profesores que hoy ha visto desmultiplicada sus diferentes instancias de lucha de derechos y demandas, así como también la poca la implicancia de las nuevas generaciones docentes en este mismo sentido. No obstante, según Polomer (2016), las organizaciones de profesores en Chile se han caracterizado por su diversidad y heterogeneidad y por la dificultad para construir instancias unitarias. Por lo tanto, históricamente, el gremio de profesores a disgregado sus demandas más allá de la multiplicación de empleadores, intereses y demandas de los profesores.

A modo de conclusión, Lantheaume y Hélou (2008), demuestran cómo las dificultades de la profesión docente organizan tanto los dolores y sufrimientos ordinarios, tanto los placeres y el reconocimiento. Pero que es más bien la incapacidad de actuar y falta de solidaridad entre los actores sociales las que pueden transformar la dificultad en sufrimiento profesional. Si bien las profesoras entrevistadas declaran satisfacción frente a la labor, los últimos años de trabajo ponen de manifiesto una cierta forma de desaliento frente a los cambios educativos que estructuran la pérdida de la autonomía y la colaboración, ahora supeditadas a los resultados estandarizados y a las continuidades políticas y económicas que no respondieron a la promesa de mejores condiciones de trabajo y de vida. Suponemos entonces que estos aspectos organizan la identidad del docente en final de carrera y que nutren una forma de sufrimiento ordinario que se construye en el cotidiano y en las perspectivas en el corto plazo del docente chileno.

Tal como lo señalan Lucero y Yarce (2018, p. 110):

El sentido de vida y trabajo se valora de acuerdo con la propia realidad y experiencias, que están articuladas a diferentes circunstancias y percepciones de las condiciones, las cuales, a su vez, determinan emociones y sentimientos que se manifiestan en la dependencia o independencia laboral, proceso que requiere ser identificado durante la preparación para la jubilación, fortaleciendo expectativas y metas que ayuden a alimentar el sentido de vida del prejubilado.

Entonces es posible sostener que la mirada sobre sobre la propia trayectoria de los docentes pueden representar casos útiles para crear un sentido de identidad profesional y continuidad en los docentes próximos al retiro de la profesión y sobre las condiciones emocionales también en que abandonan la labor docente. Las dificultades que se manifiestan en el cotidiano y que son relativamente invisibles, son a menudo manejadas individualmente en vista del frecuente aislamiento propio de la labor docente (Cau-Bareille, 2016) y más tarde del profesor jubilado. Los eventos profesionales del pasado marcan las diferencias entre entonces y ahora, y pueden ser útiles para reflexionar sobre algunos de los cambios en el sistema educativo y en la sociedad en general. A través de un análisis cuidadoso de las historias de los maestros sobre el pasado, es posible rastrear las raíces de algunos de estos cambios y discutir sus implicaciones para los maestros de hoy y de mañana (Ben-Peretz, 2002). Estimamos que la mirada regresiva del docente sobre su experiencia particular permite situar la trayectoria de la política educativa en la identidad docente, como elemento explicativo y comprensivo de la actualidad profesional y del retiro de la profesión. 


\section{REFERENCIAS}

ÁVALOS, B.; CAVADA, P.; PARDO, M.; SOTOMAYOR; C. La profesión docente: temas y discusiones en la literatura internacional. Estudios Pedagógicos, Valdivia, v. 36, n. 1, p. 235-263, 2010. Disponible en: https://scielo.conicyt.cl/scielo. php?script=sci_arttext\&pid=S0718-07052010000100013\&lng=es\&nrm=iso. Acceso en: 4 dic. 2018. http://dx.doi.org/10.4067/S0718-07052010000100013

ÁVALOS, B. ¿¿Héroes o villanos? La profesión docente en Chile. Santiago: Editorial Universitaria, 2013.

BELLEI, C. E1 estudio de la segregación socioeconómica y académica de la educación chilena. Estudios Pedagógicos, Valdivia, v. 39, n. 1, p. 325-345, 2013. Disponible en: https://scielo.conicyt.cl/scielo.php?script=sci_arttext\&pid=S071807052013000100019\&lng=es\&nrm=iso. Acceso en: 4 dic. 2018. http://dx.doi. org/10.4067/S0718-07052013000100019

BEN-PERETZ, M. Retired teachers reflect on learning from experience. Teachers and teaching, Londres, v. 8, n. 3, p. 313-323, 2002. https://doi. org/10.1080/135406002100000468

BOLÍVAR, A. Conjugar lo personal y lo político en la investigación (auto) biográfica: nuevas dimensiones en la política educacional. Revista Internacional de Educação Superior, Campinas, v. 2, n. 2, p. 341-365, 2016. https://doi.org/10.22348/riesup. v2i2.7645

BOLÍVAR, A.; DOMINGO, J.; FERNÁNDEZ, M. La investigación biográficonarrativa en educación: enfoque y metodología. Madrid: La Muralla, 2001.

CAU-BAREILLE, D. Vieillir au travail dans le champ de l'enseignement: une analyse mobilisant le modèle ergonomique et le modèle du système des activités. Nouvelle Revue de Psychosociologie, Francia, v. 2, n. 22, p. 125-142, 2016.

CHILE. Decreto de ley n. 678, de 1 de octubre de 1974. Crea el Colegio de Profesores. Diario Oficial de la República de Chile, Santiago, Chile, 16 oct. 1974. Disponible en: https://www.leychile.cl/Navegar?idNorma=6279. Acceso en: 13 dic. 2019.

CHILE. Ley n. 18.962, de 10 de marzo de 1990. Ley Orgánica Constitucional de Enseñanza. Diario Oficial de la República de Chile, Santiago, Chile, 7 marzo 1990. Disponible en: http://www.bibliotecanacionaldigital.gob.cl/visor/BND:66195. Acceso en: 13 dic. 2019.

CHILE. Ley n. 19.070, de 26 de noviembre de 1991. Estatuto Docente. Diario Oficial de la República de Chile, Santiago, Chile, 3 sept. 1992. Disponible en: https://www. leychile.cl/Navegar?idNorma=13511. Acceso en: 13 dic. 2019.

CHILE. Ley n. 19.410, de 31 de agosto de 1995. Ley sobre Estatuto de Profesionales de la Educación. Diario Oficial de la República de Chile, Santiago, Chile, 2 sept. 1995. Disponible en: https://www.leychile.cl/Navegar?idNorma=30777. Acceso en: 13 dic. 2019.

CHILE. Ley n. 20.903. Crea el sistema de desarrollo profesional docente y modifica otras normas. Diario Oficial de la República de Chile, Santiago, Chile, 1 abr. 2016. 
COLEGIO DE PROFESORES DE CHILE. Jubilación docente o la pobreza ilustrada. Un desafío para la carrera profesional. Docencia, Chile, 54, p. 78-88, dic. 2014. COLEGIO DE PROFESORES DE CHILE. ¿Qué es la deuda histórica? Santiago: Colegio de Profesores, 2018. Disponible en: http://www.colegiodeprofesores.cl/quees-la-deuda-historica/. Acceso en: 31 ago. 2018.

CORNEJO, R. El experimento educativo chileno 20 años después: una mirada crítica a los logros y falencias del sistema escolar. REICE: Revista Electrónica Iberoamericana sobre Calidad, Eficacia y Cambio en Educación, Madrid, v. 4, n, 1, p. 118-129, 2006.

CORVALÁN, J.; ROMÁN, M. La permanencia de escuelas de bajo rendimiento crónico en el cuasi mercado educativo chileno. Revista Uruguaya de Ciencia Política, Uruguay, v. 21, n. 1, p. 43-65, 2012.

COX, C. Las Políticas Educacionales de Chile en las últimas dos décadas del siglo XX. In: COX, C. (ed.). Políticas educacionales en el cambio de siglo. La reforma del sistema escolar de Chile. Santiago: Editorial Universitaria, 2003. p. 19-114.

COX, C. Construcción política de las reformas curriculares: el caso de Chile en los noventa. Profesorado, Revista de Curriculum y Formación del Profesorado, Granada, v. 10, n. 1, p. 1-24, 2006.

COX, C. Política y políticas educacionales en Chile 1990-2010. Revista Uruguaya de Ciencia Política, Uruguay, v. 21, n. 1, p. 13-42, 2012.

DONOSO, F. Memoria, labor e identidad docente. Apuntes para una historia social de los profesores de historia durante la dictadura. Santiago de Chile, 1982-1990. Paulo Freire. Revista De Pedagogía Crítica, Santiago, v. 14, p. 99-111, 2013. https://doi. org/10.25074/07195532.14.406

ELACQUA, G. The impact of school choice and public policy on segregation: evidence from Chile. International Journal of Educational Development, Países Bajos, v. 32, n. 3, p. 444-153, 2012. https://doi.org/10.1016/j.ijedudev.2011.08.003

FALABELLA, A. El mercado escolar en Chile y el surgimiento de la Nueva Gestión pública: el tejido de la política entre la dictadura neoliberal y los gobiernos de la centroizquierda (1979 a 2009). Educação \& Sociedade, Campinas, v. 36, n. 132, p. 699-722, 2015. http://dx.doi.org/10.1590/ES0101-73302015152420

FARDELLA, C.; SISTO, V. Nuevas regulaciones del trabajo docente en chile. Discurso, subjetividad y resistencia. Psicologia \& Sociedade, Belo Horizonte, v. 27, n. 1, p. 68-79, 2015. http://dx.doi.org/10.1590/1807-03102015v27n1p068

FUENTES, R.; VALDÉS, A.; CAMPOS, C. Aproximación al concepto de talento pedagógico: un paso en la selección de personas con potencial docente para la FIP en Chile. REXE: Revista de Estudios y Experiencias en Educación, Chile, v. 12, n. 23, p. 61-74, 2013.

GEERTZ, C. Thick description: toward an interpretive theory of culture. The Cultural Geography Reader, Reino Unido, p. 41-51, 2008.

GLASER, B.; STRAUSS, A. Discovery of grounded theory: strategies for qualitative research. Reino Unido: Routledge, 2017. 
LANTHEAUME, F.; HÉLOU, C. La souffrance des enseignants. Une sociologie pragmatique du travail enseignant. Paris: PUF, 2008.

LUCERO, S.; YARCE, E. Intereses de formación, motivación y sentido de vida de trabajadores en proceso de prejubilación. Educación y Educadores, Colombia, v. 21, n. 1, p. 95-113, 2018.

MARCELO GARCÍA, C. El profesorado principiante: inserción a la docencia. Barcelona: Octaedro, 2009.

MENANTEAU-HORTA, D. El rol del Estado en el desarrollo social y la Reforma de la previsión en Chile y EE. UU. Revista Austral de Ciencias Sociales, Valdivia, v. 10, p. 5-22, 2017. https://doi.org/10.4206/rev.austral.cienc.soc.2006.n10-01

MORENO-DOÑA, A.; GAMBOA, R. G. Dictadura chilena y sistema escolar: "a otros dieron de verdad esa cosa llamada educación”. Educar em Revista, Curitiba, n. 51, p. 51-66, 2014. http://dx.doi.org/10.1590/S0104-40602014000100005

NÚÑEZ,I.Educación chilena en la República: promesas de universalismo y realidades de la inequidad en su historia. Psicoperspectivas, Individuo y Sociedad, Valparaíso, v. 14, n. 3, p. 5-16, 2015. http://dx.doi.org/10.5027/psicoperspectivas-Vol14-Issue3-fulltext-617 PARCERISA, L.; FALABELLA, A. La consolidación del Estado evaluador a través de políticas de rendición de cuentas: trayectoria, producción y tensiones en el sistema educativo chileno. Education Policy Analysis Archives, Arizona, v. 25, n. 89, p. 1-24, 2017. http://dx.doi.org/10.14507/epaa.25.3177

PICAZO, M. Las políticas escolares de la concertación durante la transición democrática. Santiago de Chile: Universidad Diego Portales, 2013.

POLOMER, A. Vivir una dictadura: historia y memoria de los profesores en Chile (1973-1990). Historia 396, Viña del Mar, v. 4, n. 2, p. 187-216, 2016.

REYES, L. La escuela en nuestras manos. Las experiencias educativas de la Asociación General de Profesores y la Federación Obrera de Chile (1931-1932). Santiago: Editorial Quimantú, 2014.

SAN MARTÍN, D. Teoría fundamentada y Atlas.ti: recursos metodológicos para la investigación educativa. Revista Electrónica de Investigación Educativa, Baja California, v. 16, n. 1, p. 104-122, 2014.

SANTOS, H.; ELACQUA, G. Segregación socioeconómica escolar en Chile: elección de la escuela por los padres y un análisis contrafactual teórico. Revista de la CEPAL, Santiago, v. 119, p. 133-148, ago. 2016. Disponible en: https://repositorio.cepal.org/ bitstream/handle/11362/40396/RVE119_Santos.pdf? sequence=1\&isAllowed=y. Acceso en: 16 dic. 2019. https://doi.org/10.18356/bd46ae92-es

SISTO, V. Identidades desafiadas: individualización, managerialismo y trabajo docente en el Chile actual. Psykhe, Santiago, v. 21, n. 2, p. 35-46, 2012. http://dx.doi. org/10.7764/psykhe.21.2.542

SOTO, R.; MERA, J.; NUÑEZ, C.; SISTO, V.; FARDELLA, C. Entre la efectividad y los afectos: nuevos docentes en tiempos de nuevo management público. Athenea Digital. Revista de Pensamiento e Investigación Social, Barcelona, v. 16, n. 3, p. 3-19, 2016. https://doi.org/10.5565/rev/athenea. 1528 
VALENZUELA, J.; BELLEI, C.; DE LOS RIOS, D. Segregación escolar en Chile. In: MARTINIC, S; ELACQUA, G. (ed.) ¿Fin de Ciclo? Cambios en la gobernanza del sistema Educativo. Santiago: UNESCO, Universidad Católica, 2010. p. 209-229.

VILLALOBOS, C.; QUARESMA, M. L. Sistema escolar chileno: características y consecuencias de un modelo orientado al mercado. Convergencia, Toluca, v. 22, n. 69, p. 63-84, 2015. Disponible en: http://www.scielo.org.mx/scielo.php?script=sci_ arttext\&pid=S1405-14352015000300063\&lng=es\&nrm=iso. Acceso en: 4 dic. 2018. ZURITA, F. Represión y vigilancia hacia el Trabajo Docente durante la dictadura militar en Chile (1973-1990). Araucaria: Revista Iberoamericana de filosofía, política y humanidades, Sevilla, v. 19, n. 38, p. 285-322, 2017.

\section{SOBRE OS AUTORES}

Rosa Orellana-Fernández es doctora en ciencias de la educación por la Université Paris-Nanterre (Francia). Profesora de la Universidad Autónoma de Chile (Chile).

E-mail: rosa.orellana@uautonoma.cl

Eugenio Merellano-Navarro es doctor en actividades físicas y artísticas por la Universidad de Extremadura (España). Profesor de la Universidad Autónoma de Chile (Chile).

E-mail: emerellanon@uautonoma.cl

Adolfo Berríos-Villarroel es doctor en ciencias de la educación por la Aix-Marseille Université (Francia). Profesor de la Universidad Autónoma de Chile (Chile).

E-mail: adolfo.berrios@uautonoma.cl

Alejandro Almonacid-Fierro es doctor en actividades físicas y artísticas por la Universidad de Extremadura (España). Docente Investigador de la Facultad de Educación de la Universidad Católica del Maule; Proyecto FID UCM (Chile).

E-mail: aalmonacid@ucm.cl

Recibido el 12 de diciembre de 2018

Aprobado el 11 de septiembre de 2019 